\title{
PREPAREDNESS TO ORGANIZING A VOLUNTARY BLOOD DONATION CAMP
}

\begin{tabular}{ll}
\hline Pathology & \\
$\begin{array}{ll}\text { Mr. Raj K. } \\
\text { Motghare* }\end{array}$ & $\begin{array}{l}\text { Msc Nursing, MBA (Hosp.Admin),Clinical Nurse Cum Phlebotomist, Govt. Medical } \\
\text { College \& Hospital, Nagpur, Maharashtra, India. *Corresponding Author }\end{array}$ \\
$\begin{array}{ll}\text { Dr. Sanjay N. } & \text { MBBS,MD (PATHO), Professor \& Head Of Dept., Blood Bank, Dept. of Pathology, SSH } \\
\text { Parate } & \text { \& Govt. Medical College \& Hospital, Nagpur. }\end{array}$ \\
\hline
\end{tabular}

\section{ABSTRACT}

Introduction: Human blood is an important element of human life with no substitute. Voluntary blood donors are the cornerstone of a secure and adequate supply of blood and blood products. The safest blood donors are voluntary, non-remunerated blood donors from low-risk populations. Blood donors in India, as across the world, are of three types; voluntary donors, replacement donors and professional donors. Most donations are as a result of replacement donations, which are non-remunerated donations, provided by the relatives of patients. Professional donors are those that donate blood in exchange for money. Replacement and professional donors could also be compelled to donate blood, though their health conditions are unsuitable to donate blood. They do not help to maintain a stock of blood for emergency situations. Moreover, they do not provide rare blood groups. These points are indicating the necessity and importance of voluntary blood donations. The success of blood donation camp depends on people that organize the camp and bank team. Aim: The aim of this report is to debate about the importance of voluntary blood donation and to guide the camp organizer, medic, and also other team members involving in voluntary blood donation camp to arrange the camp efficiently.

Discussion: The aim of blood donation camp is to pick an appropriate donor whose blood is safe to the recipients, and who himself shall not in any way be harmed by blood donation. Outdoor voluntary blood donation camps in India are organized in three phases. They are pre-camp phase, camp phase, post-camp phase. Conducting voluntary blood donation camp in the regular basis will increase the stock of blood units in bank which is required for optimum functioning of the health-care system.

Conclusion: The organization of blood donation camp should be best and safe to the patient/recipients and to the donor also. With increase in population and development of more advanced medical and surgical procedures, the necessity for blood is ever increasing. Only voluntary blood donors can help to take care of an adequate supply of blood to save lots of the lives of these who in need. They were the sources of safe blood also.

\section{KEYWORDS}

\section{INTRODUCTION}

Human blood is an essential element of human life with no substitute. In many major surgeries and trauma emergencies the utilization of blood is now well accepted. Blood transfusion has been liable for saving many lives annually around the world. Yet, the number and quality of blood pool available for transfusion remains a serious concern across the world, especially within the developing countries [1]. According to World Health Organization (WHO), the estimated blood requirement for Southeast Asian region is about 16 million units per annum, but it collects just about 9.4 million units, leaving a gap of six million units $[1,2]$. India is lagging behind in blood collection in spite of its huge population of over one billion [3]. Blood donors in India, as across the world, are of three types, voluntary donors, replacement donors and professional donors.

Most donations are as a result of replacement donations, which are non remunerated donations, provided by the relatives of patients. Professional donors are those that donate blood in exchange for money. Replacement and professional donors could also be compelled to donate blood, though their health conditions are unsuitable to donate blood. They do not help to maintain a stock of blood for emergency situations. Moreover, they do not provide rare blood groups. These points indicate the necessity and importance of voluntary blood donations. Voluntary donors are non-remunerated donors and donate blood voluntarily without any inducements such as money or any other substitute of money. Such donations are providing adequate around the clock availability during emergency situationsand that they were the sources of safe blood also. Although, voluntary blood donations are increasing (45\% in 2002 to $59 \%$ 2007), still it is insufficient to meet the demands of blood needed [1]. The aim of this paper is to debate about the importance of voluntary blood donation and to guide the camp organizer, medic, and also other team members involving in voluntary blood donation camp to arrange the camp efficiently.

Organizing A Blood Donation Camp.

The outdoor camps in India are organized in places far away from blood banks, so a checklist of blood collection equipment and instruments should be maintained and carefully checked before the departure of the vehicle from the blood bank. Any omission to carry even a small item may frustrate the noble effort of the organizers, and the donors [4-7].

\section{A. Accessories to be provided by the blood bank}

The following are accessories to be provided by the blood bank:

1.List of staff attending the camp (Medical officer, blood bank technicians, nursing staff, attendants, social workers and driver).

2.Availability of vehicle

3.List of equipment to be carried to camp

- Sphygmomanometer

- Stethoscope

- Blood mixer machine

- Tube sealer

- Weighing machine

- Hemocue/Hemoglobinometer

- Refrigerated/Insulated boxes to carry blood bags

- Arm rest, hand sponges

- Linen, mattresses, pillows

- Artery forceps, scissors, tongue depressor, kidney trays, etc.

- Needle cutter

- Oxygen cylinder

- Infusion stand

- Bins for collecting infectious and non-infectious waste materials

(Note: Depending on the estimated collection of blood units, the number of each equipment varies.)

\section{List of consumables to be carried along with:}

- Single/Double/Triple blood bags - 350/450 mL capacity

- Test tubes - large and small

- Donor card with questionnaire forms

- CuSO4 solution

- Disposables lancets

- Cotton swabs, Band-Aids

- Antiseptic solution

- Antisera (optional)

- Glass slides, glass beakers, Pasteur pipettes

- Sodium hypochlorite solutions

- Emergency medicines

- Markers, donor identification stickers

- Anticoagulant solution

- Dry ice or coolant

(Note: Depending on the estimated collection of blood units, the number/volume/ quantity of each consumable/ disposable varies.)

5. Donor card, certificates and donor pins.

6.Simple and attractive incentives or awards like pen, bags, etc. are International Journal of Scientific Research 
useful in retaining donors

\section{Banners}

\section{B. Accessories to be provided by the organizers}

1.The area that is selected for voluntary blood donation camp should be well lighted, well ventilated, spacious areas. Voluntary blood donation camp should be organized in centres of public assembly, viz, educational institutions, youth groups, offices, factories, etc.

2.Arrangement of sufficient cots, tables with chair for registration, medical checkups, and for blood donation procedures.

3.Clean drinking water with disposable glasses in camp area and refreshment area.

4. Volunteers to help in registration of donor, medical checkups and refreshment after donation.

5.Placing blood donation banners at the entrance, registration areas and donation areas, etc. to guide the members of the blood donation camp and donors. A communication plan should be designed according to a good strategy like displaying posters and distributing informative leaflet at the public areas a week in advance to motivate the blood donors.

\section{Procedure/Method}

Outdoor voluntary blood donation camps in India are organized in three phases $[7,8]$.

\section{Pre-camp phase}

1.First, the organizer of blood donation camp has to contact the incharge of blood bank with official letter requesting to conduct the camp on particular date and proper place. If target segment is a residential community, it is best to conduct the camp on holiday. However, if the target segment is a college campus, factors like exam schedules and holidays should be kept in mind. Similarly, if a camp is for office goers, it can be held on a working day at the work place to make it convenient for donors.

2.A simple official letter should be given to the organization from blood bank incharge mentioning that the blood bank team will reach the venue one hour before the scheduled time, so that the blood bank team can get time to make arrangement for blood donation. Instruction should be given to the organizer to arrange a huge hall and two rooms with a facility of water, electricity and a toilet. If separate room is not available then one big hall may be converted into three separate sections using screens or curtains.

3. The blood bank has to estimate its requirement of blood units for a particular period

4.Based on the availability of blood units in their stock, they determine the number of blood units required by them through camps.

5.Blood banks take a prior permission from the state blood transfusion council (SBTC).

6.Social worker related to the blood bank visits the venue to inspect its suitability for the camp - a checklist may be provided to the organizer, the number of donations required is discussed with the organizers.

7.Few days before the camp, NGO/ social worker/ donor motivator can arrange a talk on the importance of voluntary blood donation to the potential donors.

8.Media may be approached to give adequate coverage and support to the camp.

9.Sponsors can be approached to provide financial support for media coverage, refreshment, and publicity and to honor blood donors through badges/pins.

10.Relevant correspondence should be documented for future reference.

\section{Camp Phase}

1. The blood bank team arrives at the venue of camp before the time given to donors.

2. Supervise the venue for adequate facilities like space, furniture, heaters/coolers and other equipment

3. Inspect pre-donation, donation and post-donation areas as per standards.

4. Liaise with the organizer and voluntary donor organization.

5. IEC materials and banners should be displayed everywhere.

6. Arrange a celebrity to inaugurate the camp.

7. The camp should be started on time.

The path of the donor

The 'path of the donor' refers to the areas in the voluntary blood donation camp through which the donor need to pass. The first one is usually the waiting area, at which donors enter and then pass through the donor registration area, where the registration work is done. From here they proceed to the donor testing area where hemoglobin test is done, and then to the medical officer for examination. If they are accepted as donors, they go to the second waiting area where they have to wait for their turn to enter the blood donation site or bleeding area. After donating blood they leave from the blood donation site to the resting area, then to the donors cafeteria or refreshment area where food and liquid refreshment are served by staff who also supervise the post donation period. Finally, the donors leave the voluntary blood donation camp. These areas should be properly arranged so that donors can find their way easily.

\section{Camp Phase Arrangements}

The following are six steps of camp phase arrangements

Registration: Blood donor's personal detail like name, father's name, age, address, telephone no., etc. is recorded and therefore the questionnaire is given to donors to access their present and past health status. The purpose is to pick an appropriate donor whose blood are going to be safe for a recipient.

Hemoglobin Test: This has got to be wiped out the blood donation camp itself and by the technician on duty before the donor is said fit. Blood donor's hemoglobin level are going to be checked to make sure that he/she isn't affected by anemia and may safely donate a unit of blood.

Medical Examination: A medic asks the donor certain questions on his medical record to determine that donor is fit donate blood and he will examine donors. Donor's weight, blood pressure, pulse and temperature are recorded. Only healthiness, mentally alert and physically fit individuals are accepted as blood donors.

Donation of blood: On receiving the donor from the medic, check the identity of the donor with the donor form.

1. Make necessary entries within the donors register, select appropriate bag, inspect bag for any defects and discoloration, and apply pressure to see for any leaks. The anticoagulant and additive solution should be inspected for appropriate volume, color and particulate contaminates, enter back tube no. within the donor register.

2. Prepare bag level with donor identity, unit no., blood type, date of bleeding on the bag.

3. Pass the donor and therefore the bag to the phlebotomist 4. Phlebotomist will recheck the donor identity with the bag and donor form

5. Blood is withdrawn with the assistance of a sterile and disposable kit after cleaning blood donors arm with an antiseptic solution. all at once, the method takes only 5-8 minutes.

6. Strip the donor tubing completely as possible in to the bag, starting at seal. Work quickly to stop blood from clotting within the tube. Invert bag several time to mix thoroughly, then allow tube to refill with anticoagulated blood from the bag. Repeat this procedure. 7. Care of donor after phlebotomy is extremely important. Apply pressure with sterile gauze over the aim of entry of the needle, apply bandage after bleeding stops

8. Keep the donor under observation for a few time.

9. Talk with the donor, divert his attention and

10. keep the donor comfortable. Cool and friendly environment keep the donor comfortable. After donation, allow donor to take a seat 11. the intense complication of blood donation is syncope (fainting or vasovagal syndrome) it's going to be caused by the sight of blood (psychological) or thanks to withdrawal of blood (neurophysiologic), 12. All bank technicians should conscious of this reaction and that they should keep necessary kits ready for resuscitation

13. When reaction occurs to a donor, motivator or medico-social worker should remain calm and check out to not get other donors upset and call the medical officer-in-charge of the blood collection team, but ensuring the prevention of the donor from falling down. Placing the donor on the bed or floor with a pillow under the feet, helps in subsiding minor reactions. But doctors should check up the donor altogether such cases. just in case of bleeding from the seal of venipuncture, give pressure with cotton, folding the arm with a cotton pad in between and lift the folded hand a touch upward helps in stopping such bleeding. Once the bleeding stops, the venipuncture site could even be sealed again

14. All the discarded blood bag tubing and needles need to be segregated separately for disposal as per bio-safety protocols and waste management. they ought to never be left unattended. 
15. Needles, lancet and syringes should be destroyed with the needle cutter.

16. the whole area should be cleaned with a disinfectant-sodium hypochlorite (working area and phenyl or bleaching powder- floor) after the camp is over.

17. Camp should be completed at the stipulated time.

18. The bank team should reach their destination on time

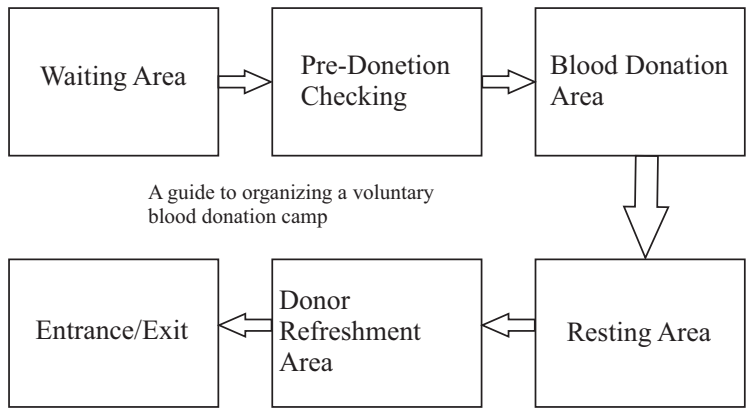

Figure 1: Afloor plan for organizing a voluntary blood donation camp

Refreshment: After donation, allow donor to take a seat within the refreshment area under observation and served with some light refreshments. The donors should be advised to stay in refreshment room for a minimum of quarter-hour and will be advised to extend their water consumption during the day and refrain from smoking for half an hour. A hearty good-bye with an invitation to the donor to donate again after three months is destined to inspire a donor to become a daily donor. The problems faced by donor in camp should be handled with tender, love, care and compassion. Donor should be made understand that refreshment has nothing to try to to with immediate recuperation of blood loss thanks to donation. A piping hot or cold drink and lightweight refreshment are offered to compel the donor to spend a while during a relaxed mood. Whatever be the things of refreshment, they ought to be served neatly and nicely with a smile. This is the last stage of the camp; it leaves a permanent impression within the mind of the donors. Talking with the donor throughout all the stages is extremely important, as it helps donors to feel happy and also helps the first time donors to get rid of their fear.

Storage of blood: The blood bag is stored as per instructions, at correct temperatures.

\section{Post-camp phase}

1. Medical director must send letters of appreciation to the organizer for arranging the camp.

2. They should be encouraged to organize similar camps on a regular basis.

3. Blood donors of the camp should receive thanks giving letters and blood group identity certificate, etc. All mandatory tests like malaria, HIV, HbsAg, HCV and syphilis will be done on the collected blood units and information given to donors, if necessary.

4. Constant touch with blood donors should be maintained through birthday cards, anniversary cards, etc. [9-11].

\section{CONCLUSION}

The purpose to organize a blood donation camp is to motivate people to donate blood and social works. The purpose of blood donation camp to pick an appropriate donor whose blood are going to be safe to the recipient and who himself shall not in any way be harmed by blood donation. Organization of blood donation camp should be best and safe to the patient/recipients and to the donor . Blood donation camp should motivate the public to donate blood by oral communication, which is the most effective method of recruiting donors. Talk about the need of blood, shortage of blood, ease of donation and myth about blood donation to the public. The speaker has the power to appeal to the humanitarian feeling of the audience. Hospital staff especially clinicians can actively contribute in motivating relatives and friends of patients to donate blood and to become regular voluntary donor. The blood bank staff should be courteous interested, cheerful and friendly, as well as professional and efficient. With increase in population and development of more advanced medical and surgical procedures, the necessity for blood is ever increasing. Only voluntary blood donors can help to maintain an adequate supply of blood to save the lives of those who are in need. Conducting voluntary blood donation camp efficiently and regularly will provide adequate round the clock availability of blood units during emergency situation and they are the sources of safe blood also. By donating blood, one gives a second chance of life to someone unknown. The blood donors become part of an exceptional group that is dedicated to alleviate the human suffering. Blood donation is a divine experience. One unit of blood saves three lives. Donating blood may reduce the risk of heart disease and stimulate the generation of red blood cells. There is no substitute for human blood. It can be acquired only from a generous blood donor.

\section{REFERENCES}

1. Available from: http://www.searo.who.int/LinkFiles/ BCT BTS-SEAR.pdf. [Las accessed on 2013 March15].

2. Soma Das, Sandip Das. Blood banks to get quality certificate. New delhi, 2009 Feb 02 Available from: http://www.financialexpress.com/news/7-bloodbanks-to-get-qualitycertificate/417881/. [Last accessed on 2013 March 15]. IJBTI - International Journal of Blood Transfusion and Immunohematology, Vol. 3, 2013. ISSN - [2230-9020]IJBTI 2013;3:12-17.www.ijbti.com Ahmed et al. 17

3. Prathama. Blood Banks \& India. 25 Sep 2009; Available from: http://www.medindia.net /healthnetwork/medblogs/general/blood-banks-andindia- 358.htm. [Last accessed on 2013 March 15]

4. Makroo RN, Blood Transfusion Therapy volume II. India: 1995.

5. Hollan S.R., Wagstaff W., Leikola J., Lothe F., Management of Blood Transfusion Service,W.H.O.: 1990.

6. Transfusion Medicine Technical Manual American Association of Blood Bank. 13 Transfusion Medicin. US: 1999 .

7. Voluntary Blood Donation Programme - an operational guideline. National AIDS Control Organization (NACO), Ministry of Health and Family Welfare Government of India, New Delhi: 2007

8. Dennis M. Smith, Roger Y. Dodd, Transfusion- Transmitted Infections, American Society of Clinical Pathologist (ASCP). Chicago: 1922.

9. Hollan SR.Optimal Use of Blood Transfusion and Immunology, Basel Karger: 1975.

10. Mukherjee K. L., Medical Lab. Technology vol-2. India: 1991.

11. Laboratory Bio-Safety Manual. 2nd edition. W.H.O. Janewa: 1993 